\title{
Immigration can alleviate the ageing problem
}

Citation for published version (APA):

Muysken, J., Corvers, F., \& Ziesemer, T. H. W. (2008). Immigration can alleviate the ageing problem. METEOR, Maastricht University School of Business and Economics. METEOR Research Memorandum No. 004 https://doi.org/10.26481/umamet.2008004

Document status and date:

Published: 01/01/2008

DOI:

10.26481/umamet.2008004

Document Version:

Publisher's PDF, also known as Version of record

\section{Please check the document version of this publication:}

- A submitted manuscript is the version of the article upon submission and before peer-review. There can be important differences between the submitted version and the official published version of record.

People interested in the research are advised to contact the author for the final version of the publication, or visit the DOI to the publisher's website.

- The final author version and the galley proof are versions of the publication after peer review.

- The final published version features the final layout of the paper including the volume, issue and page numbers.

Link to publication

\footnotetext{
General rights rights.

- You may freely distribute the URL identifying the publication in the public portal. please follow below link for the End User Agreement:

www.umlib.nl/taverne-license

Take down policy

If you believe that this document breaches copyright please contact us at:

repository@maastrichtuniversity.nl

providing details and we will investigate your claim.
}

Copyright and moral rights for the publications made accessible in the public portal are retained by the authors and/or other copyright owners and it is a condition of accessing publications that users recognise and abide by the legal requirements associated with these

- Users may download and print one copy of any publication from the public portal for the purpose of private study or research.

- You may not further distribute the material or use it for any profit-making activity or commercial gain

If the publication is distributed under the terms of Article $25 \mathrm{fa}$ of the Dutch Copyright Act, indicated by the "Taverne" license above, 
Joan Muysken, Frank Cörvers, Thomas Ziesemer

Immigration can alleviate the ageing problem

$\mathrm{RM} / 08 / 004$

JEL code: J1, J2, H3, E2, O15

\section{METE@R}

Maastricht research school of Economics

of TEchnology and ORganizations

Universiteit Maastricht

Faculty of Economics and Business Administration

P.O. Box 616

NL - 6200 MD Maastricht

phone : ++31433883830

fax : ++31433884873 


\title{
Immigration can alleviate the ageing problem
}

\author{
Joan Muysken ${ }^{\mathrm{a}, \mathrm{d}}$ \\ Frank Cörvers ${ }^{\mathrm{b}}$ \\ Thomas Ziesemer \\ Maastricht University \\ The Netherlands
}

\section{Abstract:}

This paper analyses the way immigration can help to alleviate the burden ageing presents for the welfare states of most Western Economies. We develop a macroeconomic framework which deals with the impact of both ageing and immigration on economic growth. This is combined with a detailed model of the labour market, to include the interaction with unemployment, while distinguishing between low- and high-skilled labour. The empirical relevance of some crucial model assumptions are shown to hold for the Netherlands, 1973 - 2005. The conclusions are that immigration will help to alleviate the ageing problem, as long as the immigrants will be able to find work. Moreover, the better educated the immigrants are or become, the higher their contribution to growth will be.

Key words: ageing; immigration; unemployment; skills.

\footnotetext{
${ }^{a}$ Department of Economics, Maastricht University.

${ }^{\mathrm{b}}$ Research Centre for Education and the Labor Market (ROA), Maastricht University.

${ }^{c}$ UNU/MERIT and Department of Economics, Maastricht University.

${ }^{\mathrm{d}}$ Corresponding author: Prof. dr. J. Muysken, Department of Economics, Faculty of Economics and Business Administration, Maastricht University, address: P.O. Box 616, $6200 \mathrm{MD}$ Maastricht, The Netherlands, tel.: ++31(0)43-3883821, fax: ++31(0)43-3884150, email: j.muysken@algec.unimaas.nl.
} 


\section{Introduction}

The European Union has recently adopted a new immigration policy, which includes the introduction of the 'blue card', a European green card. Apart from this group of highly skilled migrants, also the admission and procedures for seasonal workers, paid trainees and intra-corporate transferees will be regulated during the next few years (see EP, 2007). The new policy aims at solving skill shortages resulting from an ageing population. According to Eurostat figures the over-65 population is anticipated to rise from 15.4 percent in 1995 to 22.4 percent by 2025 , and the working-age population will shrink by over 50 million by 2050 (EU, 2005a).

According to Freeman (2006) immigration has been very important to tackle skill shortages in the U.S., even though the greying of the labour force is less severe than in Europe. His analysis shows that skill shortages due to an increasing demand for highlyskilled workers are prevented by both an increasing proportion of foreign born welleducated workers in US multinational firms all over the world, and a large flow of immigration of in particular scientists and engineers. These developments have been made possible by the strong rise of the population in many developing countries, and the spread of mass education to many of these low-wage countries.

In this paper we investigate under which conditions immigration contributes to solving a lack of labour supply that results from an ageing population. It is obvious that immigration alone cannot account for keeping our GDP at a high level, and we also need other measures like a rising rate of labour force participation, particularly in the older age classes (Cichon et al., 2003). Therefore we also include the ratio of the working age population to the total population in both our theoretical and empirical analysis. With respect to the empirical analysis we simply take the case of the Netherlands to illustrate our theoretical reasoning of how immigration can alleviate the ageing problem. In that context it is interesting to note that in the Netherlands there are many concerns among citizens, politicians and the CPB Netherlands Bureau of Economic Policy Analysis - an official independent research institute informing the Dutch government - on more liberal immigration policies (see e.g. Muysken et al. 2007).

Although the blue card seems to be a good instrument to attract more higher educated individuals, we show that it may be beneficial for the European Union to attract 
also immigrants who are not graduated from universities as long as the skill distribution of the immigrants is on average not below that of the EU countries. It is, however, very important that immigrants are in paid employment, so that the goods and services they produce can be consumed by the growing share of the population that has retired. Also intuitively the skill level of immigrants should be of second importance as long as they work, since low-skilled working immigrants can pay for the pensions of the retired people as well as the benefits of the unemployed natives. Jobs for these immigrants can be available in for example construction, cleaning, security, personal care and domestic activities. ${ }^{1}$ Therefore the immigration policy of the European Union regarding the blue card, even when it is extended to regulate the admission of for example seasonal workers, may be too restrictive to maximize the benefits from immigration in the light of an ageing population. We show that the benefits from immigration could proliferate further if policy makers focus on an increase of the ratio of the working to the inactive population in general. The aim of our theoretical and empirical analysis is to illustrate the relevance of this ratio, in particular in relation to immigration.

Most of the literature on the impact of immigration on ageing focuses on the impact of immigration on the labour market and the welfare state - see Nannestad (2007) for an overview. A drawback of this focus then is that the impact of ageing and immigration on capital formation and economic growth usually are ignored. Razin and Sadka (1999, 2000) were the first who analysed the impact of immigration on ageing in a general equilibrium context, taking this impact into account.

A difficulty with general equilibrium analysis in this context is that it usually models the labour market in a highly stylised way, assuming full employment. But for the typical European welfare state the interaction between immigration, unemployment and ageing problems cannot be ignored. The ideal solution would be to develop a general equilibrium model which includes both the impact of ageing and immigration on economic growth, and models the interaction with unemployment in a satisfactory way. The problem is that such a model leads to a full-blown macroeconomic model, which can

\footnotetext{
${ }^{1}$ See Wilson et al. (2007) for the employment opportunities in elementary and low-skill occupations in the European Union.
} 
only be solved by means of simulation (Boeri and Brückner, 2005). Its underlying properties then remain hard to analyse. At this moment we therefore prefer a different route: We present a simple macroeconomic model as a background for our analysis of the impact of immigration on ageing and economic growth in Western economies. The properties of that model are in line with the model of Razin and Sadka. Moreover, our model is flexible enough to allow for the inclusion of unemployment. Finally, an attractive feature of our macroeconomic model is that it pays explicit attention to the importance of social equilibrium.

To elaborate on the impact of unemployment and immigration in our macroeconomic model, we develop a model of the labour market which focuses on the interaction between immigration, unemployment and ageing problems, while ignoring the impact of capital formation on economic growth. However, contrary to most models of the labour market, we include capital as a production factor. Capital is modeled to be substitutable with high-skilled labour in a nested CES-production structure, where the other component is low-skilled labour. This also allows for more flexibility in the substitution between high and low skilled labour compared to the Cobb-Douglas production function which is usually assumed in this type of analysis (Kemnitz, 2003; Krieger, 2004; Boeri and Brückner, 2005). Moreover, instead of the usual simple monopoly union model, we assume right-to-manage wage bargaining.

Since we use capital as a production factor, we can use the insights of the simple macroeconomic model to discuss the interaction between economic growth, the labour market and the welfare state in a discursive way. This enables us to analyse the mechanisms which can be used to explain the results when using a full-blown macroeconomic model. Moreover, several interesting insights result from our analysis, which lead beyond the insights of using a Razin and Sadka type general equilibrium model or a labour market model separately. For instance we analyse simultaneously the impact of immigration on economic growth, while taking into account the interaction with both unemployment and ageing.

The set up of our paper is as follows. We present the simple macroeconomic model in section 2 and use this for a first discussion of the impact of immigration on the problems for the welfare state resulting from ageing. Then we present an elaborate model of the 
labour market in section 3 and use the insights from that model for a more elaborate discussion of the impact of immigration on welfare state and ageing problems. We argue that an important element of that impact is the extent to which immigration has a positive effect on the activity rate. For that reason we investigate for the Netherlands to which extent such an effect could be found in section 4, together with other predicted effects from our analysis. We find that the empirical implications of our model can be corroborated for the Netherlands. Since we find a positive effect of immigration on the activity rate over the last decades, we conclude that indeed for the Netherlands immigration can be used to alleviate the ageing problem. We elaborate and generalise this notion in our concluding remarks in section 5 .

\section{Decline of economic growth in an ageing economy}

We present a simple macroeconomic model as a background for our analysis of the impact of immigration on ageing in Western economies. The model is in line with that of Razin and Sadka, although with more emphasis on the social equilibrium. In our model the younger generation ('young' for short) is working, saves and pays pension contributions, whereas the older generation ('old' for short) lives from pension benefits and dissavings. Economic growth is enhanced by savings. We show that the latter implies that an ageing economy experiences a decline in economic growth. Immigration then might counter this decline.

\subsection{The general framework}

Our analysis starts from the identity $Y=w . E+r . K$, where $Y, E$ and $K$ represent GDP, employment and capital, respectively. We model a small open economy, such that the interest rate $r$ is determined by the world interest rate $r^{*}$. We assume that on average wage negotiations lead to a nominal wage growth which is equal to inflation and productivity growth. The share of labour income in GDP, $\alpha$, then is fixed and real wages $w$ are given by:

$\mathrm{w}=\alpha . \mathrm{Y} / \mathrm{E}$ 
while the capital output ratio follows from:

$\mathrm{K} / \mathrm{Y}=(1-\alpha) / \mathrm{r}^{*}$

Capital accumulation equals investment $I$, taking into account depreciation at a rate $\delta$ :

$\mathrm{K}=\mathrm{I}+(1-\delta) \cdot \mathrm{K}_{-1}$

The young contribute a share $t$ of their income to pension benefits of the old in a pay-asyou-go system. ${ }^{2}$ The young both earn wages and have income from capital - we assume the young to own a share $\varphi$ of the capital stock. Disposable income of the young, $\mathrm{Y}^{\mathrm{y}}$, then equals:

$\mathrm{Y}^{\mathrm{y}}=(1-\mathrm{t}) \cdot\left[\mathrm{w} \cdot \mathrm{E}+\mathrm{r} . \mathrm{I}+\mathrm{r} \cdot(1-\delta) \cdot \varphi \mathrm{K}_{-1}\right]$

The young consume a share $c$ of their disposable income.

Disposable income of the old, $Y^{\circ}$, consists of their income from capital and the pension benefits financed by the young:

$\mathrm{Y}^{\mathrm{o}}=\mathrm{r} .(1-\delta) \cdot(1-\varphi) \cdot \mathrm{K}_{-1}+\mathrm{t} \cdot\left[\mathrm{w} \cdot \mathrm{E}+\mathrm{r} . \mathrm{I}+\mathrm{r} \cdot(1-\delta) \cdot \varphi \mathrm{K}_{-1}\right]$

The old do not only consume their disposable income, but also their capital stock at a rate $\xi$ - hence their dissavings equal $\xi .(1-\delta) .(1-\varphi) . K_{-1}$.

Equilibrium in the economy is based on two conditions. First macroeconomic equilibrium requires equality between savings and investment. Second social equilibrium requires that consumption per capita of the old is at least equal to a conctant fraction $\eta$ of consumption per capita of the young - this is the rationale for pension contributions of the young. We elaborate both equilibrium conditions below.

\footnotetext{
${ }^{2}$ We include premiums for unemployment in the analysis in the next section.
} 


\subsection{Macroeconomic equilibrium}

Strictly speaking the macroeconomic equilibrium condition of a small open economy is not equality of investment and savings, because the current account should be included. However, we ignore the impact of the current account in our analysis for simplicity and leave the dynamics of the current account for further research. ${ }^{3}$ This implies that we focus on the equality between savings and investment as an equilibrium condition.

Domestic savings equal savings of the young minus dissavings of the old:

$\mathrm{S}=(1-c) \cdot \mathrm{Y}^{\mathrm{y}}-\xi \cdot(1-\delta) \cdot(1-\varphi) \cdot \mathrm{K}_{-1}$

Investments lead to capital accumulation at a rate $g$. Equality between investments and savings then yields: ${ }^{4}$

$\mathrm{g}=\left\{\mathrm{t}^{\prime} \cdot\left[1-\mathrm{d}^{\prime}\right]-\left[\delta \cdot(1-\alpha)+\xi \cdot \mathrm{d}^{\prime}\right]\right\} /\left[1-\alpha-\mathrm{t}^{\prime}\right]$

with $t^{\prime}=(1-t) \cdot r \cdot(1-c)$ and $d^{\prime}=(1-\varphi) \cdot(1-\alpha) \cdot(1-\delta)$.

Equation (6) shows the rate of growth of capital consistent with macroeconomic equilibrium, conditional on the other parameters of the model. We are in particular interested in the relation with the rate of contribution $t$.

The relation between the rate of growth $g$ and the contribution rate $t$ from equation (6) is presented in Figure 1. We name this relationship the IS-curve, since for each combination of rate of growth and contribution rate savings equal investment.

The intuition behind the downward sloping nature of the curve is that a higher contribution rate leads to a lower rate of growth, since less funds are available for investment. The curve will shift upwards when the propensity to consume $c$ decreases, since more income then will be saved at the same contribution rate. The same occurs when the old dissave less, that is when $\xi$ decreases or $\varphi$ increases. Finally, a higher share

\footnotetext{
${ }^{3}$ See Boeri and Brückner (2005) for an analysis including capital mobility, although they ignore both the impact on economic growth and on the current account, too. Another point for further research is that nonwestern immigrants are responsible for a large share of income transfers abroad.

${ }^{4}$ We use the equalities $I=(\delta+g) . K_{-1}$ and $w \cdot E=\{\alpha /(1-\alpha)\} . r .(1+g) . K_{-l}$.
} 
of labour income $\alpha$ and a higher interest rate $r$ also lead to an upward shift of the IScurve.

\subsection{Social equilibrium}

Social equilibrium requires that consumption per capita of the old is at least equal to a constant fraction $\eta$ of consumption per capita of the young. This is a matter of social responsibility, since the old have contributed in their young days to the development of the economy as it is now for the young. ${ }^{5}$ Moreover, political reality requires that the old have sufficient benefits, since they represent a growing part of the electorate in an ageing economy. Social equilibrium then requires:

$\eta . c . Y^{\mathrm{y}} / \mathrm{N}^{\mathrm{y}}=\left[\mathrm{Y}^{\mathrm{o}}+\xi .(1-\delta) .(1-\varphi) \cdot \mathrm{K}_{-1}\right] / \mathrm{N}^{\mathrm{o}}$

where $N^{y}$ and $N^{o}$ represent the number of young and old, respectively. ${ }^{6}$ The term in brackets of equation (7) is consumption of the old.

Substituting equations (3) and (4) in equation (7) yields:

$\mathrm{g}=\mathrm{d}^{\prime} \cdot[1+(1+\xi / \mathrm{r}) /\{\chi-\mathrm{t} \cdot(1+\chi)\}]-1$

with $\chi=\eta . c .\left(N^{o} / N^{y}\right)$. Equation (8) shows the rate of growth of capital consistent with social equilibrium, conditional on the other parameters of the model. Again, we are in particular interested in the relation with the rate of contribution $t$. It is obvious that there is a positive relationship between the rate of growth $g$ and the contribution rate $t$, as long as the latter is not too high. ${ }^{7}$ We assume this to be the case since a positive relationship is intuitively plausible: A higher rate of growth implies higher consumption growth of the young relative to the old when the contribution rate is low. This may compensate the effect that a higher premium increases consumption of the old relative to that of the young.

\footnotetext{
${ }^{5}$ For the moment we ignore another aspect of social equilibrium, which is that unemployed young should receive a fraction $\gamma$ of wages. We include unemployment in the analysis in section 3 .

${ }^{6}$ As long we ignore unemployment, we have $N^{y}=E$.

${ }^{7}$ Thus $t<\chi /(1+\chi)$ should hold.
} 
The social equilibrium equation (8) is presented as the increasing SE- curve in Figure 1. The curve will shift downwards when the number of old increases relative to young (a higher ratio $N^{o} / N^{y}$ ). In that case a higher contribution is needed at the same rate of growth to obtain social equilibrium. The same holds when the share $\eta$ is higher, or the propensity to consume $c$ has increased. Finally the curve shifts upwards in case of a lower share in labour income $\alpha$ and a lower return on investment $r$.

Figure 1 De IS-curve en de SE-curve

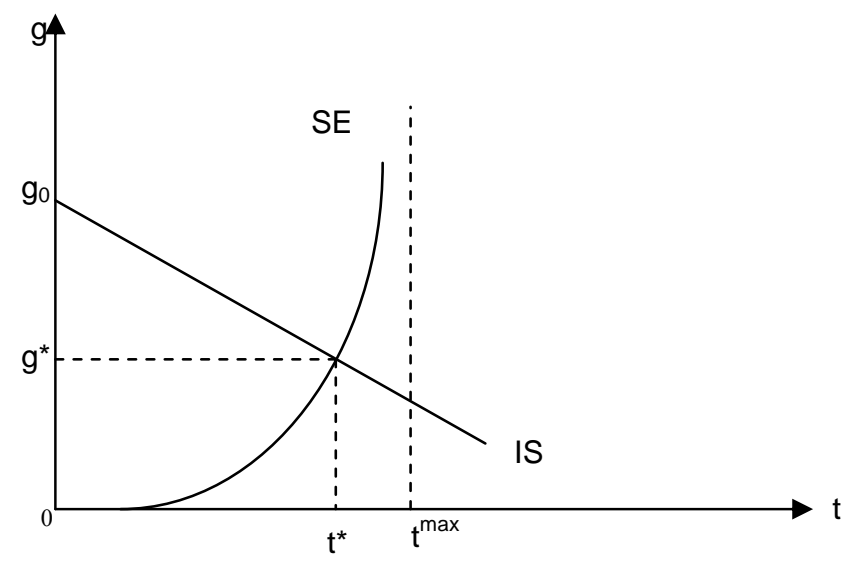

\subsection{Economic growth in an ageing economy and the impact of immigration}

In our simple model growth is determined by equality of savings and investment on the one hand and social equilibrium on the other. In terms of Figure 1 this occurs on the intersection of the IS-curve and the SE-curve, at a rate of growth $g^{*}$. The rate of contributions then is $t^{*}$. Since in our model both the interest rate and the share of labour income are fixed, the capital output ratio is fixed too and output growth equals the growth of capital.

For a proper understanding of the mechanisms leading to economic growth we start in an economy without old, i.e. everybody is working. In that case the young own all capital $(\varphi=1)$ and pay no contributions $(t=0)$. The SE-curve then does not play a role in the analysis and from the IS-curve (6) it follows that the rate of growth is given by: 
$g^{\prime}=(1-\delta) \frac{1-c}{\frac{1-\alpha}{r}-(1-c)}-\delta$

This rate of growth is above $g_{0}$ in Figure 1 and resembles strongly the rate of growth that follows from the Harrod-Domar model, or the AK-model. ${ }^{8}$ One should realise that in these models the growth rate of output also equals that of capital and is determined by the ratio of the propensity to save $(1-c)$ and the capital-output ratio $(1-\alpha) / r$, together with the rate of depreciation $\delta$. Population growth, which equals employment growth, does not affect this growth rate: its impact is neutralised by wage growth which equals exogenous productivity growth. ${ }^{9}$

By distinguishing between young and old, one introduces a group of persons who are not involved in production and require contributions from the employed workers. The resulting income transfer from young to old $(t>0)$, together with dissavings from the old, lead to a lower rate of growth $g^{*}$.

It follows from the analysis above that ageing of the economy induces a downward shift of the SE-curve, following an increase in the ratio of old to young, $N^{o} / N^{y}$. This leads both to a lower rate of growth and a higher rate of contributions.

From that perspective it is not surprising that economic policy is focusing on reducing the ratio old relative to young - or more precisely, to increase the ratio of the working to the inactive population. One way to enhance this process is to increase the retirement age - in the model some 'old' then become 'young' and the SE-curve shifts upwards in Figure 1. Another way is to encourage immigration which usually consists of young This would lead to and upward shift in both the IS-curve and the SE-curve. In both

\footnotetext{
${ }^{8}$ We don't model endogenous growth here, however. An interesting extension of our model would be to introduce human capital. An alternative approach can be found in Kemnitz (2001) who models endogenous growth using a $Y=A . L$ model. Endogenous growth follows from a proportional impact of physical capital per capita on $A$. Immigration then only has a positive impact on economic growth when the immigrants contribute a higher amount of physical capital per capita than the incumbent population does.

${ }^{9}$ Our approach here typically is a medium run approach since we allow capital to change and have an impact on production, but the fixed capital output ratio presumes that adjustments to a steady state still have to occur. The medium run approach is also consistent with the assumption of a constant $\alpha$ on average and the equality between $S$ and $I$.
} 
cases a higher rate of growth can be realised without increasing the rate of contributions. In our view this is also intuitively understood by both the United Nations and the European Union in their advise to allow for more immigration (UN, 2000; EU, 2005).

As we mentioned earlier, our analysis is in line with that of Razin and Sadka. Their analysis assumes that immigrants enter the economy at an age where they can start to work immediately and therefore contribute to pensions of the elderly population, without drawing benefits themselves. As long as immigration does not lead to a lower wage rate and the interest rate remains fixed anybody will profit according to Razin and Sadka. ${ }^{10}$ In our analysis this follows from the impact of an upward shift in the SE-curve in Figure 1, which leads to both a higher rate of growth and lower premiums.

Razin and Sadka also argue that when the wage rate does not remain fixed, the situation is no longer clear. In case of a falling wage rate, the income of workers decreases, while that of pensioners increases. It then depends of the elasticity of substitution between labour and capital, whether interest income will compensate the loss in wages sufficiently population wide - the rise in the capital-labour ratio following immigration due to increases savings will be complemented by a declining interest rate. In terms of our analysis: the latter causes a decrease of the IS-curve in our Figure 1 and an increase of the SE-curve. The rise in the ratio young-old will also lead to an upward shift of the SE-curve. However, Razin and Sadka also assume a fixed income for pensioners, implying a decrease in $\eta$, the ratio of consumption per capita of the old to that of the young, and therefore inducing a decrease of the SE-curve. The outcome then is indeed ambiguous.

A shortcoming of our above analysis is that we have assumed full employment to prevail, consistent with the analysis of Razin and Sadka. However, the typical Western European economy is characterised by the prevalence of unemployment, which also imposes a serious burden on the welfare state. Moreover, immigrants are prone to become unemployed too. We include these two points in our analysis by adding a model of the labour market to the above analysis. This is taken up in the next section.

\footnotetext{
${ }^{10}$ Krieger (2004) points out that a crucial assumption of Razin and Sadka is that second-generation immigrants have identical properties to the incumbent population. However, if this second generation is lower educated and grows faster than the incumbent population, immigration might have a negative impact.
} 


\section{The impact of immigration on the labour market}

A drawback of the analysis of Razin and Sadka is that they assume full employment to prevail at all times. This point has been taken up by Kemnitz (2003), who analyses the impact of immigration on an ageing economy, while allowing for unemployment. However, a disadvantage of Kemnitz' analysis is that he ignores the impact of savings on economic growth in order to keep the analysis manageable. The same holds for Boeri and Brückner (2005) in their elaborate analysis of the impact of immigration on the labour market and the welfare state. (Moreover Boeri and Brückner do not analyse the impact of ageing.) Both studies therefore implicitly sacrifice the general equilibrium context, to allow for a much richer analysis of the impact of immigration on the welfare state. We will initially follow that route also in this section.

We generalise Kemnitz' analysis in several respects, for instance by distinguishing physical capital as a separate production factor. Through the impact of capital accumulation we then use the insights of the simple macroeconomic model of the previous section to discuss the interaction between economic growth, the labour market and the welfare state in a discursive way. This leads our analysis both beyond that of Razin and Saka, and beyond that of Kemnitz and Boeri and Brückner.

\subsection{The production structure and wage formation}

Output $Y$ is produced according to a nested CES-production function:

$$
Y=\left[\lambda . L^{-\rho}+\left[\partial . H^{-\phi}+\imath . K^{-\phi}\right]^{\frac{\rho}{\phi}}\right]^{-1 / \rho} \quad \sigma=\frac{1}{1+\rho} \geq 0
$$

where $H$ and $L$ is employment of high-skilled and low-skilled workers, respectively, and $K$ is capital. Low-skilled labour has a constant elasticity $\sigma$ with capital and high-skilled labour. The latter form a complex $F$ with a constant elasticity of substitution, $\varsigma$ :

$$
F(H, K)=\left[\partial . H^{-\phi}+t . K^{-\phi}\right]^{-\frac{1}{\phi}} \quad \varsigma=\frac{1}{1+\phi} \geq 0
$$


When $\varsigma=0$, capital and high-skilled labour are complements, as is sometimes assumed in the literature. ${ }^{11}$

This formulation of the production structure is much more general than Razin and Sadka (2000), who use an infinite elasticity $\sigma$ since they assume perfect substitutability, and Kemnitz (2003), who assumes the elasticity of subtitution to be unity $(\sigma=1)$ since he uses a Cobb-Douglas production function. ${ }^{12}$

Profit maximisation by the firm implies that marginal productivities should equal factor prices. Hence, when the low-skilled wage is $w$, the high-skilled wage is $w_{H}$ and the interest rate is $r$, we find:

$$
\begin{aligned}
& w=\frac{\partial Y}{\partial L}=\lambda \cdot\left[\frac{Y}{L}\right]^{\frac{1}{\sigma}} \\
& w_{H}=\frac{\partial Y}{\partial H}=\left[\frac{Y}{F}\right]^{\frac{1}{\sigma}} \cdot \partial \cdot\left[\frac{F}{H}\right]^{\frac{1}{\varsigma}} \\
& r=\frac{\partial Y}{\partial K}=\left[\frac{Y}{F}\right]^{\frac{1}{\sigma}} \cdot . \cdot\left[\frac{F}{K}\right]^{\frac{1}{\varsigma}}
\end{aligned}
$$

The workforce consists of $N_{H}$ and $N_{L}$ high-skilled and low-skilled persons, respectively. The high-skilled labour market is competetive, which implies that the wage rate $w_{H}$ is determined by full employment for all high-skilled persons. ${ }^{13}$

For low-skilled workers the wage is determined by union bargaining, where the union takes both the employment of high-skilled workers, which follows from labour supply, and the capital stock as given - the interest rate is exogenous. We assume a rightto-manage model, where the bargaining power by unions equals $\varepsilon$ - this encompasses Kemnitz' (2003) monopoly union model by setting $\varepsilon=1$, and Razin and Sadka's (2000)

\footnotetext{
${ }^{11}$ Kemnitz (2003) uses this assumption to ignore capital in his analysis.

${ }^{12}$ The Cobb-Douglas production function is also used in Casarico and Devillanova (2003) and Krieger (2004) - and in more encompassing, applied models like Boeri and Brückner (2005).

${ }^{13}$ This is also assumed in Kemnitz (2003). It is relatively easy to extend the model for separate wage bargaining of high-skilled workers, see Boeri and Brückner (2005) for an ad hoc application in a similar model of the labour market.
} 
full competition when $\varepsilon=0$. Denoting the level of unemployment benefits by $b$ and assuming a tax rate $t_{b}$ to finance these benefits, the expected income of a low-skilled worker is $(1-u) \cdot t_{b} \cdot w+u \cdot b$, where $u$ is the low-skilled unemployment rate, $u=\left(N_{L}-\right.$ $L) / N_{L}$. The firm negotiates about the wage given its capital stock and employment of high skilled workers. The resulting problem then is found by maximising: ${ }^{14}$

$\Omega=\left[L \cdot w\left(1-t_{b}\right)+\left(N_{L}-L\right) \cdot b\right]^{\varepsilon} \cdot[Y-w \cdot L]^{1-\varepsilon}$

with respect to $w$, subject to equation (11a), and given $K$ and $H$. This yields: ${ }^{15}$

$w=\frac{\varepsilon \cdot \sigma / \psi(w)-(1-\varepsilon) \cdot\left(N_{L}-L\right) / L}{1-(1-\varepsilon \cdot \sigma) / \psi(w)} \cdot \frac{b}{1-t_{b}} \quad$ with $\quad \psi(w)=\lambda \cdot\left[\frac{w}{\lambda}\right]^{1-\sigma}$

where $\psi(w)$ is the low-skilled labour share in income as a function of the low-skilled wage, and $\psi^{\prime}(w)<0$ when $\sigma>1$. Equation (13) can not be solved explicitly for $w$, due to the non-linear nature of $\psi(w)$. For that reason we use a linear approximation of the first part of the right hand side, such that:

$w=\left[\frac{\varepsilon \cdot \sigma / \lambda-(1-\varepsilon) \cdot\left(N_{L} / L-1\right)}{1-(1-\varepsilon \cdot \sigma) / \lambda}-\varepsilon \cdot(v / b) \cdot(1-\sigma) \cdot w\right] \cdot \frac{b}{1-t}$

does hold, where $v>0$ is a constant. This reproduces the important the properties the right hand side of (13) following from $\psi^{\prime}(w)<0$ when $\sigma>1$. The wage rate then is given by: ${ }^{16}$

$w=\frac{\varepsilon \cdot \sigma-(1-\varepsilon) \cdot \lambda \cdot\left(N_{L} / L-1\right)}{[(1-t)+\varepsilon \cdot v \cdot(1-\sigma)] \cdot[\lambda-(1-\varepsilon \cdot \sigma)]} b$

${ }^{14}$ See also Jackman et al. (1989), as discussed in Carlin and Soskice (1990), pp. $393 \mathrm{ff}$.

${ }^{15}$ This is consistent with Kemnitz' (2003) result when we assume a monopoly union and a Cobb-Douglas function, i.e. $\delta=1$ and $\sigma=1$.

${ }^{16}$ Again, this is consistent with Kemnitz' (2003) result when we assume a monopoly union and a CobbDouglas function, i.e. $\delta=1$ and $\sigma=1$. 
Thus the negotiated low-skilled wage is a mark-up on the benefit level, which decreases with an increase in unemployment as seems plausible. A rise in the tax rate will lead to an increase in the mark-up, while a rise in low-skilled labour augmenting technological change will decrease the mark-up. It is also interesting to note that an increase in the elasticity of substitution leads to a higher mark-up, since low-skilled labour then can easier take over the role of high-skilled labour.

\subsection{Social equilibrium in the presence of unemployment}

It is obvious that the extension of our analysis to include unemployment also has implications for the social equilibrium in our macroeconomic model of the previous section. Social equilibrium then does not only require that the young pay a contribution at a rate $t$ to finance consumption of the old, but also that the employed young pay taxes at a rate $t_{b}$ to finance their unemployed colleagues.

Analogous to the pay-as-you-go system in the pension contributions for the old it seems reasonable to assume that government will set the tax and benefit rates such that unemployment benefits are covered by tax revenues. Since we focus on low-skilled unemployment, we assume that the benefits are paid by taxes on the low-skilled wage only. ${ }^{17}$ That is, given a certain level of benefits $b$, consistency with a tax rate $t_{b}$ requires:

$\mathrm{t}_{\mathrm{b}} \cdot \mathrm{W} \cdot \mathrm{L}=\mathrm{b} \cdot\left(\mathrm{N}_{\mathrm{L}}-\mathrm{L}\right)$

As a consequence we find, combining equations (14) and (16), for the rate of unemployment $u:^{18}$

$1-L / N_{L}=\frac{t_{b} \cdot \varepsilon \cdot \sigma}{\lambda .(1-\varepsilon \cdot t)-(1-\varepsilon \cdot \sigma)+t_{b}+\varepsilon \cdot(1-\sigma) \cdot[\lambda-(1-\varepsilon \cdot \sigma)]}=u\left(\lambda, \varepsilon, \sigma, t_{b}\right)$

\footnotetext{
${ }^{17}$ This assumption, which is in line with Kemnitz (2003), is motivated by analytical tractability. Including benefits paid by high skilled workers complicates the analysis considerably, without altering the qualitative results.

${ }^{18}$ A similar equation is used by Boeri and Brückner (2005), although they introduce this equation ad hoc.
} 
Equation (17) shows that full employment prevails under perfect competition $(\varepsilon=0)$, which is consistent with the findings of Razin and Sadka (2000). Kemnitz' (2003) result is found for a monopoly union $(\varepsilon=0)$ and a unit elasticity of substitution $(\sigma=1)$.

One should realise that in the above analysis either the tax rate $t$ or the benefit level $b$ is endogenous. Kemnitz (2003) assumes the tax rate $t$ to be determined a priori by government. In our analysis then benefits $b$ would follow from substituting equations (11a) and (17) in equation (16). However, in line with the reasoning underlying the SEcurve and the approach more commonly used in the literature - e.g. for instance Boeri and Brückner (2005) - we assume that government sets a replacement rate $\beta$, and then derives the tax rate from substituting $b=\beta . w$ in equation (16). That is, the tax rate $t_{b}$ * then is solved from:

$\mathrm{t}_{\mathrm{b}} *=\beta \cdot \mathrm{u}\left(\lambda, \delta, \sigma, \mathrm{t}_{\mathrm{b}} *\right) /\left[1-\mathrm{u}\left(\lambda, \delta, \sigma, \mathrm{t}_{\mathrm{b}}^{*}\right)\right]$

Unemployment then follows from substituting the solution of equation (18) in equation (17), which yields $u^{*}=u\left(\lambda, \delta, \sigma, t_{b}^{*}\right)$. We find the familiar result that unemployment is higher the larger the replacement rate - see for instance Boeri and Brückner (2005). Finally, an important observation is that from the analysis above it follows that the unemployment rate of low-skilled workers, $u^{*}$, is not affected by the supply of low skilled workers.

It is obvious that the extension of our analysis to include unemployment also has implications for the social equilibrium in our macroeconomic model of the previous section. Social equilibrium then does not only require that the young pay a contribution at a rate $t$ to finance consumption of the old, but also that the employed young, if low skilled, pay taxes at a rate $t_{b} *$ to finance their unemployed colleagues.

In equation (3) the tax rate $t_{b} *$ then has to be added to the premium $t$ and the social equilibrium equation (8) has to be adjusted correspondingly. Both the IS-curve and the SE-curve in Figure 1 then shift upwards when unemployment decreases. The intuition for the SE-curve is obvious: fewer persons have to receive a contribution which implies a 
lower premium and hence more room for growth. For the IS-curve the lower premium implies that more income will be saved and hence more capital accumulation will occur.

\subsection{The impact of immigration on the labour market}

In line with Razin and Sadka (2000) and Kemnitz (2003) we assume that immigration is concentrated on low-skilled workers - any immigration of high-skilled workers only makes our case stronger. Since the unemployment rate of low-skilled workers, $u^{*}$, is not affected by supply of low-skilled workers one might infer that low-skilled employment of the incumbent population does not decrease - this is indeed found by Kemnitz (2003). ${ }^{19}$ This seems a result of quite strong assumptions, however.

A plausible qualification is that discrimination with respect to low-skilled immigrant workers might occur. This might have two effects. First it might lead to a lower chance of finding a job. That is, while an incumbent low-skilled worker has a probability $\ell=L / N_{L}$ of finding a job, a migrant worker might have a probability $\delta_{\eta} \ell$ with $\delta_{\eta}<1$ of finding a job (Boeri and Brückner, 2005). Second, instead of earning the lowskilled wage $w$, the migrant worker might earn $\delta_{w} w$ with $\delta_{w}<1$. The first effect will lead to a higher incidence of unemployment for immigrants. The second effect might compensate the first effect, but since it will usually coincide with working in inferior jobs we do not expect that to be the case (see also Müller, 2003). Therefore if anything, we expect immigration to lead to a decrease in the rate of unemployment of low-skilled native workers.

An important qualification, however, results from the impact of capital accumulation, which brings us to the interaction with our simple macroeconomic model. For simplicity we initially assume that the rate of low-skilled unemployment remains constant.

From equation (15) one sees that the low-skilled wage rate is decreasing in the rate of unemployment. Assuming that the rate of unemployment is not affected, the low-skilled

\footnotetext{
${ }^{19}$ Kemnitz points out rightly, however, that although the rate of unemployment of low-skilled workers is not affected by immigration, the overall rate of unemployment increases because immigrants have a higher incidence to become unemployed relative to the average native person.
} 
wage rate will not change. ${ }^{20}$ One sees then from equation (11a) that output will increase proportionally with low-skilled employment. Since high-skilled labour is fully employed, this immediately implies that income per capita after immigration will be higher than prior to immigration. The question then is how this increased income per capita is distributed.

From equations (11b) and (11c) one also sees that both high-skilled work and capital become more productive after an increase of low skilled labour supply, since $Y / F$ increases. Because high skilled labour is fixed in supply, the higher productivity implies that the wage rate for high-skilled labour will increase. But for capital, the higher productivity implies that since the interest rate is fixed, demand for capital will increase. This can be facilitated by the increase in savings from employed immigrants and highskilled workers. Because the share of labour income in the economy increases, immigration leads towards an upward shift in the IS-curve in terms of our analysis in Figure 1.

The increased share of labour income will also lead to a downward shift in the SE-curve. But more important is the direct impact of immigration on the SE-curve through increase in the ratio young to old, $N^{y} / N^{o} .{ }^{21}$ This will lead towards an upward shift in the SE-curve.

As follows from the upward shifts in both the IS-curve and the SE-curve, economic growth will increase unequivocally due to immigration - this is consistent with our observation that income per capita will increase. The impact on net wages is harder to determine without further information, however. When the SE-curve shifts upwards more that the IS-curve does, this will imply that pension contributions $t$ will decrease - the tax rate $t_{b}$ is not affected by immigration, since the neither the rate of unemployment nor the low-skilled wage rate are. Moreover, because the high-skilled wage increases relative to the low-skilled wage, the contributions will decrease even stronger for the low-skilled wages. Therefore low-skilled workers will profit from immigration. If on the other hand, the upward shift in the SE-curve is less that that of the IS-curve, the low-skilled workers

\footnotetext{
${ }^{20}$ Kemnitz (2003) finds that the low-skilled wage rate decreases due to immigration since he assumes a variable replacement rate $b$. Razin and Sadka (2000) in their full employment model also find a decreasing wage rate since marginal productivity of labour decreases.

${ }^{21}$ In terms of the parameters of our model, we assume the elasticity $\kappa$ of the share of labour income $\alpha$ with respect to the ratio young to old, $N^{y} / N^{o}$, to be small, i.e. $\kappa<[(1-\alpha)(1-t) \chi] /[\alpha(1-t) \chi-\alpha t]$.
} 
will probably not profit from immigration. Whatever the case, high-skilled workers will profit from immigration since they become relatively scarcer. The impact of capital income on income for low-skilled and high-skilled workers cannot be determined, nor can the impact on the income of the old. However, the old will definitely profit from the increased wage income of the working population. A more detailed analysis of the impact of immigration on the income distribution will require a numerical solution of the model. ${ }^{22}$ But an interesting finding is anyhow that income per capita will increase due to immigration.

This last conclusion might no longer hold when unemployment increases due to immigration, as we discussed above. In that case, the low-skilled wage rate will decrease and the impact of immigration on both the income per capita and on the various groups in the economy becomes less clear. This would require a further specification of the model and probably numerical simulation.

An important conclusion of the above analysis is that the incorporation of the impact of capital accumulation in our model leads to new insights. In terms of Figure 1, the partial model of the labour market assumes a horizontal IS curve and the impact of immigration then follows from shifts in the SE-curve, while ignoring the impact of capital accumulation. It is obvious, however, that the increase in capital accumulation following immigration, is an important element when analysing the impact of immigration. This should not be ignored.

\section{Some empirical evidence regarding the impact of active relative to inactive persons}

In sections 2 and 3 some results were derived theoretically in regard to the relation of active to inactive persons. We want to provide some empirical evidence for them using data for the Netherlands. In addition we want to show that indeed in the past immigration has had a positive impact on this relation.

\footnotetext{
${ }^{22}$ Given L from (10) and $H=N_{H}$, we can solve for $K$ from equation (11.c), given the interest rate fixed at $\mathrm{r}$. Substituting $K$ and $L$ in equation (11.b) then determines $w_{H}$.
} 
The data are taken from the World Development Indicators with the exception of the following. Skill shares of the labour force are taken from Cambridge Econometrics, wage data are based on own calculations from CBS (Statistics Netherlands) data, migration data and employment data also come from the CBS. We use gross fixed capital formation data for investment.

As econometric method we use least squares with heteroscedasticity and autocorrelation-corrected standard errors. To take the impact of lagged regressors properly into account, the variable has been formulated as a polynomial distributed lag of the first degree with sufficient lags (Greene 2003, p. 566). We provide t-values in parenthesis, whereas in the case of the polynomial distributed lag the coefficient and the t-values refer to the sum of the coefficients. All variables turn out to have no unit roots when we run regressions for them with economically meaningful chosen exogenous regressors, rather than univariate tests only. ${ }^{23}$

\subsection{The impact of the activity rate on growth}

In section 2 we showed that the ratio of active over inactive persons, the activity rate $N^{y} / N^{o}$ in our model, has a positive impact on the growth rate. The growth rate was defined as the change of the capital stock, given its past value. The crucial point therefore is a positive impact of the activity rate on investment, captured here as the investment/GNI ratio $I / Y$ in order to take into account that economies are growing. We do not use the ratio of young over old people but rather the labour force, $L$, over the total population, $P$. As the data always contains some aspects of the business cycle, we also include the interest rate $r$ and the growth rate of GDP per capita $g_{Y / P}$. Our first hypothesis then is as follows.

$\mathrm{I} / \mathrm{Y}=\mathrm{a}_{0}+\mathrm{a}_{1} \cdot(\mathrm{L} / \mathrm{P})+\mathrm{a}_{2} \cdot \mathrm{r}+\mathrm{a}_{3} \cdot g_{Y / P}+\varepsilon_{1}$

Our hypothesis then is that $a_{1}>0$, i.e. the activity rate has a positive impact on growth.

\footnotetext{
${ }^{23}$ The detailed estimation results can be provided by the authors. For all regressions we have a low number of observations. It not very hard to derive different outcomes, but in all cases this had strange impacts on the results regarding the control variables. We therefore prefer the results presented here.
} 
For the investment-growth equation we get:

$$
\begin{aligned}
\mathrm{I} / \mathrm{Y}= & -1.71-4.67 \ln (\mathrm{L} / \mathrm{P})-2.95[\ln (\mathrm{L} / \mathrm{P})]^{2}+0.278\left(\mathrm{E}_{\mathrm{hrs}} / \mathrm{P}\right)^{2}-0.278 \mathrm{r}+0.3^{*} \mathrm{~g}_{\mathrm{Y} / \mathrm{P}} \\
& (-5.46)(-5.56)
\end{aligned}
$$

Adj. $\mathrm{R}^{2}=0.87$; $\mathrm{DW}=1.82$. Obs.: $1983-2005$

The equation shows a good fit. All regressors are significant at the $0.2 \%$ level (one fifth of $1 \%$ ). To take the impact of cyclical fluctuations properly into account, the interest rate has been formulated as a polynomial distributed lag of the first degree with five lags. The coefficient and the t-values then refer to the sum of the coefficients.

One sees that the $\mathrm{L} / \mathrm{P}$ ratio has a negative impact on the investment ratio. It is not enough to raise only the L/P ratio. What clearly matters is that people are not only in the labour force but also do work, as assumed in the model of section 2. $E_{h r s}$ denotes the yearly hours worked by the population. The employment variable here has a clearly positive impact on the investment ratio. The crucial point of an increase in the L/P ratio then is that employment must also increase in order to stimulate investment.

\subsection{The impact of the activity rate on unemployment}

In section 3 it was shown that an increase of the low-skilled labour force has no impact on the unemployment rate of the unskilled. As the overall unemployment rate would be a weighted average of the unemployment rate of the low-skilled and the high-skilled workers, an increase in the ratio of active to inactive people should have no impact unless the skill composition would change. Our hypothesis therefore is that the unemployment rate $u$ depends on the relative skill shares, $N^{L} / N^{H}$, but insignificantly so on the ratio of active over inactive persons, $L / P$. We control for wages, $w$, GDP per capita growth, $g_{Y / P}$, a time trend $t$ to allow for policy changes and lagged unemployment to account for hysteresis. The following equation summarizes the hypothesis:

$$
u=b_{0}+b_{1} u_{-1}+b_{2} \cdot N^{L} / N^{H}+b_{3} \cdot w+b_{4} \cdot g_{Y / P}+b_{5} \cdot t+b_{6} \cdot L / P+\varepsilon_{2}
$$


According to the hypothesis, $b_{6}$ should be insignificant whereas the other coefficients should be significant.

For the unemployment rate we get the following results:

$$
\begin{aligned}
& \mathrm{u}-\mathrm{u}_{-1}=579.7-0.76 . \mathrm{u}_{-1}+10.97\left(\mathrm{~N}^{\mathrm{L}} / \mathrm{N}^{\mathrm{H}}\right)^{2}-38.61 \mathrm{~g}_{\mathrm{LP},-1}+67.48 . \mathrm{g}_{\mathrm{Y} / \mathrm{P}}-1832.9\left(\mathrm{~g}_{\mathrm{Y} / \mathrm{P}}\right)^{2} \\
& \quad(6.53)(-16.9) \quad(4.65) \\
& +49.78 . \ln (\mathrm{Y} / \mathrm{P})_{-1}-12.34 . \mathrm{w}+0.34 . \mathrm{w}^{2}+0.973 . \mathrm{t}+5.84 . \ln (\mathrm{L} / \mathrm{P})_{-1} \\
& \quad \begin{array}{l}
(7.46) \\
\quad(-4.16)
\end{array}
\end{aligned}
$$

Adj. $\mathrm{R}^{2}=0.9$; $\mathrm{DW}=2.29$; Obs.: 1981- 2003 .

From the estimation results one sees that the unemployment rate depends on its own past value. It increases with the ratio of low to high skilled workers, which seems plausible because in the past immigrants and their children had a lower education and accounted for a high proportion of the unemployed. A high growth rate of the $L / P$-ratio has a negative impact on the unemployment rate, but its level is insignificant as we hypothesised. Wages have a U-shaped impact with a positive effect above $18 €$. Growth rates of the GDP per capita have an inverted U-shaped impact with a maximum of $1.84 \%$ as in the theory of Aghion and Howitt (2004), which means that only above that value growth reduces the rate of unemployment. This probably reflects a business cycle impact, because the level of the GDP per capita and a time trend, taken alone yielding a longterm growth rate of $1.95 \%$, also enter significantly. Taken together these two growth results imply that only growth above the trend decreases unemployment rates.

The last variable is significant only at the $80 \%$ level as predicted by the theoretical model of section 2 . All other regressors are significant at a level below $0.2 \%$. In short, if immigration brings about a higher $\mathrm{L} / \mathrm{P}$ ratio, this will not have a positive impact on the unemployment rate, unless it also increases the ratio of low to high skilled workers. Policy should aim at keeping this ratio unaffected by migration and schooling. 


\subsection{The impact of immigration on the activity rate}

Finally, we claim in the above sections that immigration would enhance the active population and therewith, when linked back to the first equation, enhance growth. The ratio of the labour force and the population, $L / P$, is used as the indicator of active to inactive persons, because it includes not only the old persons but also working or not working children. This ratio should depend on migration as a share of the population, $\mathrm{im} / \mathrm{P}$, on emigration as a share of the population, $\mathrm{em} / \mathrm{P}$, and on fertility, frt, measured as the expected number of children born in a year per woman in the childbearing years. Moreover, we capture ageing by the life expectancy at age zero, leo. Since part of the labour force enters the labour market because of the favourable business cycle, for example pupils not finishing school because of the good economic situation, we also use GDP per capita, $Y / P$, as a regressor. Finally, we include a time trend and the lagged value of the dependent variable. The hypothesis then can be formulated as follows.

$\mathrm{L} / \mathrm{P}=\mathrm{c}_{0}+\mathrm{c}_{1} \cdot(\mathrm{L} / \mathrm{P})_{-1}+\mathrm{c}_{2} \cdot \mathrm{leo}+\mathrm{c}_{3} \cdot \mathrm{Y} / \mathrm{P}+\mathrm{c}_{4} \cdot \mathrm{t}+\mathrm{c}_{5} \cdot \mathrm{fer}+\mathrm{c}_{6} \cdot \mathrm{im} / \mathrm{P}+\mathrm{c}_{7} \cdot \mathrm{em} / \mathrm{P}+\varepsilon_{3}$

The impact of migration on the $\mathrm{L} / \mathrm{P}$ ratio can be shown as follows.

$$
\begin{aligned}
& \mathrm{L} / \mathrm{P}-\mathrm{L}_{-1} / \mathrm{P}_{-1}=-0.81-1.115(\mathrm{~L} / \mathrm{P})_{-1}+0.0045 \mathrm{leo}_{-1}+0.00003 . \mathrm{t}^{2}+0.098 . \ln (\mathrm{Y} / \mathrm{P}) \\
& (-2.5) \quad(-10.81) \\
& -0.00095 . \mathrm{t}^{*} \mathrm{DUMM}_{\mathrm{PRE} 80}-0.0075 . \mathrm{frt}+ \\
& (-11.23)
\end{aligned}
$$

Adj. $R^{2}=.895 ; \mathrm{DW}=2.22$. Obs.: 1973-2005.

Because of the endogeneity problem with the GDP per capita we have used a two-stage procedure using the lagged value as an instrument. Fertility, immigration and emigration are modelled as linear polynomial distributed lags with 9, 11, and 13 lags respectively. The reason is that fertility has delayed effects through parents staying at home, possibly 
leaving the labour force for some time. Immigrants have higher than average fertility behaviour and children of immigrants who are not captured by the fertility variable if they immigrate too, are captured by the lag of the immigration variable when entering the labour force. If emigrants leave with children, these children are missed as persons entering the labour force later. The effect of emigration probably is insignificant, because the L/P ratio has an order of magnitude of .5 and if a working couple with two kids emigrates this decreases the numerator by 2 and the denominator by 4 persons, leaving it about unchanged.

With respect to the other variables: As there seems to be a break in the labour force data of the ILO/ WDI, we have used an intercept and a slope dummy to correct for this. The intercept dummy was insignificant. Life expectancy, time trend and GDP per capita increase the L/P ratio. Hence all variables have the expected signs.

Ageing requires a higher number of active persons. Our evidence shows that it is possible to increase the labour force-population ratio via immigration. However, if too many immigrants or their children later do not get jobs or are insufficiently skilled this may increase the unemployment rate and thereby outweigh the advantages of more working people. In addition investment will diminish and might go abroad.

\section{Concluding remarks}

In this paper we have extended the work of Razin and Sadka (2000), Kemnitz (2003), Kriecher (2004) and Boerie and Brückner (2005) by analysing immigration in a general equilibrium context, including physical capital in a CES production function, using a right-to-manage wage bargaining model, and allowing for unemployment. The main conclusion from the theoretical model is that income per capita will increase due to immigration, under the condition that unemployment does not increase due to immigration. The highly-skilled workers will profit anyway from the usual low skilled immigration, and there may be important distributional effects for the low-skilled and the retired. The increase in capital accumulation following immigration, turns out to be an important determinant of economic growth when analysing the benefits of immigration. 
Our empirical analysis for the Netherlands reveals that there are least two conditions that must be satisfied in order to get a positive impact of immigration on the economy. First, immigrants should get employed to stimulate economic growth. Second, the proportion of low-skilled immigrants in the total number of immigrants should not be higher than the proportion among natives to prevent unemployment from rising. Thus to stimulate investments and economic growth it is of utmost importance that immigration policy as a means to mitigate the aging problem should not only focus on the number of immigrants, but also on their employability by keeping the skill structure in line with the skill distribution of domestic labour market entrants. This requires two steps: (1) skill neutral screening of immigrants and (2) an education policy that has the ambition and ability to educate the second and third generations of immigrants, at least in line with the average skill distribution in a country.

Our conclusions support the view of the European Commission that immigrants in general have a positive impact on the economy provided that they are employed. As the European Commission puts it: "the current situation and prospects of EU labour markets can be broadly described as a 'need' scenario. Some Member States already experience substantial labour and skills shortages in certain sectors of the economy, which cannot be filled within the national labour markets. This phenomenon concerns the full range of qualifications - from unskilled workers to top academic professionals.” (EU, 2005a, p. 4). In line with this statement by the European Commission we argue, following our theoretical and empirical results, that the immigration policy of the European Union with respect to the blue card and the admission of some other specific groups is too restrictive to maximize the benefits from immigration in the light of an ageing population.

Finally, the expectations from immigration as a single cure for falling birth rates and an ageing population should not be too high, since it is only one policy instrument within a broader mix. Moreover, many countries in the European Union should worry about their high unemployment and low employment rates, and give more priority to increase employment. Immigration policies should go hand in hand with active labour market policies and education policies to get the low-skilled unemployed back to work and to prevent young people, both natives and immigrants, from early school leaving, thereby raising their level of education and opportunities on the labour market. 


\section{References}

Aghion, P. and P. Howitt, 1994, Growth and Unemployment, Review of Economic Studies, 61 (3), 477-494.

Boeri, T. and H. Brückner, 2005, European migration, Economic Policy, 44, 629 - 703.

Carlin, W. and D. Soskice, 1990, Macroeconomics and the wage bargain, Oxford University press, Oxford.

Casarico, A. and C. Devillanova, 2003, Social Security and Migration with Endogenous Skill Upgrading, Journal of Public Economics 87(3-4), 773-797.

Cichon, M., R. Léger and R. Knop, 2003, White or Prosperous: How much migration does the ageing European Union need to maintain its standard of living in the twentyfirst century?, International Labour Office, Geneva.

European Parliament, 2007, Resolution on 26 September 2007 on the Policy Plan on Legal Migration, Brussels.

EU, 2005, Green Paper on an EU approach to managing economic migration, COM (2004), 811 final, Brussels.

EU, 2005a, Policy Plan on Legal Migration, COM(2005) 669 final, Brussels.

Freeman, R.B., 2006, Is a great labour shortage coming? Replacement demand in the global economy, NBER Working Paper No. 12541, New York.

Greene, W.H., 2003, Econometric Analysis, Fifth Edition, Prentice Hall, Pearson International Edition.

Jackman, R., R. Layard, S. Nickell and S. Wadwhani, 1989, Unemployment, unpublished manuscript.

Kemnitz, A., 2001, Endogenous Growth and the Gains from Immigration, Economics Letters, 72 (2), 215-218.

Kemnitz, A., 2003, Immigration, Unemployment and Pensions, Scandinavian Journal of Economics, 105 (1), 31-47.

Krieger, T., 2004, Fertility rates and skill distribution in Razin and Sadka's migrationpension model: A note, Journal of Population Economics, 17, 177-182.

Müller, T. ,2003, Migration, Unemployment and Discrimination, European Economic Review 47(3), 409-427. 
Muysken, J., T. Ziesemer and F. Cörvers, 2007, Immigratie als wapen in de strijd tegen de vergrijzing, Kwartaalschrift Economie, forthcoming.

Nannestad, P., 2007, Immigration and welfare states: A survey of 15 years of research, European Journal of Political Economy, 23 (2), 512-532.

Razin, A. and E. Sadka, 1999, Migration and Pension with International Capital Mobility, Journal of Public Economics,74(1), 141-150.

Razin, A. and E. Sadka, 2000, Unskilled Migration: A Burden or a Boon for the Welfare State?, Scandinavian Journal of Economics, 102(3), 463-479.

United Nations, 2000, Replacement Migration: Is it a Solution to Declining and Aging Populations?, UN Population Division, New York.

Wilson, R.A., F. Cörvers, B.Gardiner, B. Kriechel, H. Pollitt, I. Livanos and U. Chewpreecha, 2007, Medium-term forecasts of occupational skill needs in Europe: Synthesis Report, Warwick Institute for Employment Research, Research Centre for Education and the Labour Market, Cambridge Econometrics, Final report for Cedefop, version 1.1, December, University of Warwick, Coventry. 